\title{
Säulenchromatographische Bestimmung von Aminosäuren im Serum von Nor- malpersonen sowie magenresezierten und gastrektomierten Patienten vor und nach einer Probemahlzeit
}

\author{
Von J. Breuer, Gerda Kaese und H. Breuer \\ Aus dem Institut für Kliuische Biocbemie der Universität Bonn
}

(Eingegangen am 8. April 1968)

\author{
Herrn Professor Dr. med., Dr. rer. nat. Ernst Schütte qum 60. Geburtstag genvidmet
}

\begin{abstract}
Bei 7 leber- und magengesunden Normalpersonen, 10 Patienten mit Billroth-I-Anastomose, 10 Patienten mit Billtoth-II-Anastomose und 7 gastrektomierten Patienten wurden die Aminosäuren im Serum des Nüchternbluts quantitativ bestimmt; die Enteiweißung des Serums erfolgte mit 5proz. Sulfosalicylsäure und die Auftrennung der Aminosäuren durch Chromatographie an Ionenaustauschersäulen. Die mittleren Konzentrationen der Aminosäuren bei den 4 untersuchten Personengruppen zeigten keine statistisch signifikanten Unterschiede.

Bei 5 Normalpersonen und bei 6 gastrektomierten Patienten, die wegen eines Carcinoms operiert worden waren, wurden die Konzentrationen der Aminosäuren vor sowie 1/2, 1, 2 und $3 \mathrm{Stdn}$. nach Verabreichung einer Probemahlzeit (300 g Quark) bestimmt. Sowohl bei den Normalpersonen als auch bei den gastrektomierten Patienten wurde ein Anstieg fast aller Aminosäuren im Serum beobachtet. Die höchsten Konzentrationen der Aminosäuren wurden bei den Normalpersonen 1 Std., bei den Gastrektomierten dagegen bereits $1 / 2$ Std. nach Beendigung der Probemahlzeit gefunden. Trotz des unterschiedlichen Resorptionsprofils war die Gesamtmenge der nach einer Probemahlzeit im Serum nachgewiesenen Aminosäuren etwa gleich groß.

Die Ergebnisse der vorliegenden Untersuchung zeigen, daß die Hydrolyse von Eiweiß und die Resorption von Aminosäuren bei gastrektomierten Patienten im Vergleich zu Normalpersonen nur gering verändert sind.
\end{abstract}

The amino acids were quantitatively determined in the serum from fasting blood of 7 normal subjects with healthy liver and stomach, 10 patients with Billroth-I-anastomosis, 10 patients with Billroth-II-anastomosis and 7 patients after gastrectomy. Deproteination of the serum was carried out by the addition of equal amounts of $5 \%$ sulfosalicylic acid. The amino acids were separated by ion exchange chromatography. The average values obtained for the various amino acids did not show any statistically significant differences in the 4 groups of subjects.

The concentrations of amino acids in the serum of 5 normal subjects and 6 gastrectomised patients, who had been operated for stomach carcinoma, was determined before and after a test meal ( $300 \mathrm{~g}$ cottage cheese), at $1 / 2,1,2$ and 3 hour intervals. The normal subjects as well as the patients showed an increase in all the amino acids. In normals, the highest concentrations were reached after 1 hour, whereas in the gastrectomised patients the highest concentrations were observed as early as $1 / 2$ hour after the test meal. In spite of the difference in the resorption profile, the total amounts of the different amino acids investigated was almost of the same order of magnitude.

These results clearly indicate that the hydrolysis of protein and the resorption of amino acids in gastrectomised patients do not differ as compared to normal subjects.

Die quantitative Bestimmung von Aminosäuren im Serum und Plasma mit Hilfe der Säulenchromatographie ist durch die Einführung automatisierter Verfahren wesentlich erleichtert worden. Dies hat dazu geführt, daß während der letzten Jahre in zahlreichen Arbeiten über das Verhalten der Aminosäuren im Blut des Menschen unter Normalbedingungen sowie bei verschiedenen Erkrankungen berichtet worden ist. Im Mittelpunkt des Interesses standen dabei vornehmlich akute und chronische Leberkrankheiten (vgl. 1-5). Dagegen ist über die Konzentrationen von Aminosäuren im Serum magenresezierter und gastrektomierter Patienten unseres Wissens bisher kaum etwas bekannt $(6,7)$. Im Hinblick auf die Bedeutung des Magens und des Dünndarms für die Resorption schien es deshalb wichtig, das Verhalten der Aminosäuren im Serum nach verschiedenen Formen der Magenresektion eingehender zu studieren. In der vorliegenden Arbeit werden die Ergebnisse vergleichender Untersuchungen bei Patienten nach Billroth-I-Anastomose, nach Billroth-II-Anastomose sowie nach Gastrektomie mitgeteilt. Um die nach der Entfernung des Magens veränderten Resorptionsverhältnisse besser beurteilen zu können, wurden außerdem die AminosäurenKonzentrationen im Serum vor sowie zu verschiedenen Zeiten nach Verabreichung einer Probemahlzeit bei gastrektomierten Patienten untersucht und mit den Werten bei Normalpersonen verglichen. Es zeigte sich, $\mathrm{da} \beta$ die Konzentrationen der Aminosäuren im Serum bei Normalpersonen sowie bei magenresezierten und gastrektomierten Patienten etwa gleich groß sind, während der Anstieg der Aminosäuren nach einer Probemahlzeit bei gastrektomierten Patienten im Vergleich zu Normalpersonen deutlich beschleunigt ist.

\section{Methodik}

Chemikalien, Lösungen und Puffer

Asparagin (Fa. Serva Entwicklungslabor, Heidelberg) und Glutamin (Fa. Fluka AG, Buchs SG, Schweiz) waren „puriss.“; die Aminosäuren waren von p. a. Reinheitsgrad (Fa. Serva Entwicklungslabor, Heidelberg). Methanol wurde vor Gebrauch destilliert. Caprylsäure und Thiodiäthylenglykol waren „puriss.“ (Fa. Fluka AG, Buchs SG, Schweiz). Brij 35, Ninhydrin "puriss.“ und Hydrindantin p. a. wurden von der Fa. Serva Entwicklungs- labor, Heidelberg, bezogen. Alle weiteren verwendeten Chemikalien waren von p. a. Reinheitsgrad (Fa. E. Merck, Darmstadt). Wasser als Lösungsmittel wurde mit Hilfe eines Ionenaustauschers deionisiert. Die Standard-Aminosäuren-Lösung enthielt 18 Aminosäuren in Konzentrationen von je $2,5 \mathrm{mMol} / l$ ( $\mathrm{Fa}$. Technicon, Frankfurt/Main) und wurde vor Gebrauch mit $0,1 \mathrm{~N} \mathrm{HCl}$ verdünnt (Endkonzentration der Aminosäuren 0,1 mMol/l). Die Zusammensetzung der Pufferlösungen für die Elution ist in Tabelle 1 angegeben. 
Tab. 1

Zusammensetzung der Citrat-Pufferlösungen für die Elution von Aminosäuren von Ionenaustauschersäulen

Die Pufferlösungen werden in Kunststoff-Flaschen bei $-15^{\circ}$ aufbewahrt. Die Aufnahme von Ammoniak setzt die Gebrauchsfähigkeit der Reagenzien herab

\begin{tabular}{|c|c|c|c|c|}
\hline \multirow[t]{2}{*}{ Bestandteile } & \multicolumn{4}{|c|}{ Pufferlösung } \\
\hline & $\mathbf{A}$ & B & C & D \\
\hline \multirow{4}{*}{$\begin{array}{l}\text { tri-Natriumci- } \\
\text { trat-2-hydrat } \\
\text { Natriumchlorid } \\
\text { Wasser } \\
\text { Natronlauge } \\
\text { (2N) }\end{array}$} & $58,84 \mathrm{~g}$ & $58,84 \mathrm{~g}$ & $58,84 \mathrm{~g}$ & $58,84 \mathrm{~g}$ \\
\hline & - & - & - & $233,79 \mathrm{~g}$ \\
\hline & $3200 \mathrm{ml}$ & $3400 \mathrm{ml}$ & $3600 \mathrm{ml}$ & $3600 \mathrm{ml}$ \\
\hline & $100 \mathrm{ml}$ & $100 \mathrm{ml}$ & $100 \mathrm{ml}$ & $100 \mathrm{ml}$ \\
\hline Methanol & $400 \mathrm{ml}$ & $200 \mathrm{ml}$ & - & - \\
\hline Caprylsäure & $4 \mathrm{ml}$ & $4 \mathrm{ml}$ & $4 \mathrm{ml}$ & $4 \mathrm{ml}$ \\
\hline $\begin{array}{l}\text { Thiodiäthylen- } \\
\text { glykol }\end{array}$ & $20 \mathrm{ml}$ & $20 \mathrm{ml}$ & $20 \mathrm{ml}$ & - \\
\hline Brij 35-Lösung & $40 \mathrm{ml}$ & $40 \mathrm{ml}$ & $40 \mathrm{ml}$ & $40 \mathrm{ml}$ \\
\hline $\begin{array}{l}\text { Salzsäure } \\
\text { Wasser }\end{array}$ & $\begin{array}{l}\text { etwa } 80 \mathrm{ml} \\
\text { ad } 4000 \mathrm{ml}\end{array}$ & $\begin{array}{l}\text { etwa } 80 \mathrm{ml} \\
\text { ad } 4000 \mathrm{ml}\end{array}$ & $\begin{array}{l}\text { etwa } 70 \mathrm{ml} \\
\text { ad } 4000 \mathrm{ml}\end{array}$ & $\begin{array}{l}\text { etwa } 20 \mathrm{ml} \\
\text { ad } 4000 \mathrm{ml}\end{array}$ \\
\hline pH-Wert & 2,87 & 2,87 & 3,80 & 10,00 \\
\hline
\end{tabular}

* Die Einstellung des pH-Wertes erfolgt auf genau 0,02 Einheiten durch Zugabe von Salzsäure

\section{Säulenchromatographie}

Die Auftrennung der Aminosäuren erfolgte mit Hilfe eines 5-Säulen-Aminosäurenanalysators der Fa. Technicon, Frankfurt/ Main. Die Chromatographierohre hatten eine lichte Weite von $6 \mathrm{~mm}$ und eine Länge von $140 \mathrm{~cm}$; sie waren bis zu einer Höhe von $130 \mathrm{~cm}$ mit einem sauren Kationenaustauscherharz (Chromobead Typ A der Fa. Technicon, Frankfurt/Main) gefüllt. Bei dem Harz handelt es sich um ein sulfoniertes Polystyrol, das zu $8 \%$ mit Divinylbenzol quer vernetzt ist; es liegt in sphärischen Partikeln von $17 \pm 2 \mu \mathrm{m}$ Durchmesser (8) vor.

Nach dem Auftragen der enteiweißten Serumproben und der Standard-Aminosäuren wurde unter Verwendung der „Autograd-Technik" mit verschiedenen Puffersystemen eluiert. Das genaue Elutionsschema ist in Tabelle 2 angegeben. Die Arbeits-

Tab. 2

Elutionsschema für die Trennung von Aminosäuren an Ionenaustauscherharz

Die Chromatographierohre wurden mit Chromobeadharz Typ A der Fa. Technicon (Frankfurt/Main) gefüllt; die Elution der Aminosäuren erfolgte unter Verwendung der Autograd-Technik (vgl. "VarigradTechnik" nach PETERSON und SOBER (16) sowie PIEZ und MORRIS (17))

\begin{tabular}{|c|c|c|c|c|c|}
\hline \multirow[b]{2}{*}{ Kammer } & \multicolumn{2}{|c|}{ Puffer } & \multicolumn{3}{|c|}{ Endkonzentrationen von } \\
\hline & Gemisch & $\mathrm{ml}$ & $\mathrm{Na}^{+}(\mathrm{Val})$ & Methanol (\%) & pH-Wert \\
\hline $\begin{array}{l}1 \\
2 \\
3\end{array}$ & \multirow{3}{*}{$\left.\begin{array}{l}\mathbf{A} \\
\mathbf{B} \\
\mathbf{B} \\
\mathbf{B}^{*} \\
\mathbf{C}\end{array}\right\}$} & \multirow{3}{*}{$\left.\begin{array}{r}75 \\
75 \\
75 \\
5 \\
70 \\
75 \\
75 \\
75 \\
75 \\
75\end{array}\right\}$} & $\begin{array}{l}0,2 \\
0,2 \\
0,2\end{array}$ & $\begin{array}{r}10 \\
5 \\
5\end{array}$ & $\begin{array}{l}2,87 \\
2,87 \\
2,87\end{array}$ \\
\hline 4 & & & 0,2 & 0 & $2,87-3,8$ \\
\hline $\begin{array}{l}5 \\
6 \\
7 \\
8 \\
9\end{array}$ & & & $\begin{array}{l}0,2 \\
1,2 \\
1,2 \\
1,2 \\
1,2\end{array}$ & $\begin{array}{l}\mathbf{0} \\
\mathbf{0} \\
\mathbf{0} \\
\mathbf{0} \\
\mathbf{0}\end{array}$ & $\begin{array}{r}3,8 \\
10,0 \\
10,0 \\
10,0 \\
10,0\end{array}$ \\
\hline
\end{tabular}

* Dieses Gemisch enthielt keinen Zusatz von Methanol

temperaturen der Chromatographiesäulen betrugen während der ersten $61 / 2$ Stdn. der Analyse $60^{\circ}$ und in den nächsten 3 Stdn. $40^{\circ}$. Wäl Irend der letzten Stunde der Analyse wurde die Temperatur von 40 auf $60^{\circ}$ erhöht. Bei einer Analysendauer von $10^{1} / 2 \mathrm{Stdn}$. betrugen die Durchflußmenge $0,9 \mathrm{~m} / \mathrm{Min}$. und der Druck 300 bis 400 pounds/square inch.

Die Ausmessung der Aminosäurengipfel exfolgte halbautomatisch mit einem Technicon Integrator/Kalkulator (TIC). Die quantitative Bestimmung von Prolin und Citrullin wurde nach einem früher (9) angegebenen Verfahren durçhgeführt.

\section{Versucbe zur Enteineißung der Serumproben}

Das Serum wurde unmittelbar nach der Blutentnahme in üblicher Weise gewonnen. Um festzustellen, welche Methode zur Entei- weißung der Serumproben am besten geeignet ist, wurden folgende Versuche durchgeführt: Aliquote Teile der selben Serumproben wurden mit dem gleichen Volumen 5proz. Sulfosalicylsäure, 10proz. Sulfosalicylsäure oder 20proz. Trichloressigsäure versetzt bzw. in einer Collodiumhülse (Membranfilter-Gesellschaft Göttingen) bei $2000 \mathrm{~g}$ für $30 \mathrm{Min}$. zentrifugiert (10). Anschließend wurden die enteiweißten Proben der Aminosäurenanalyse unterworfen. Die Ergebnisse dieser Untersuchungen sind in Tabelle 3

Tab. 3

Wirkung verschiedener Enteiweißungsmethoden auf die Konzentrationen der Aminosäuren im Serum von 5 gesunden Versuchspersonen. Es wurden die Seren von 3 Frauen (Alter 23, 24 und 28 Jahre) und 2 Männern (Alter 33 und 34 Jahre) untersucht. Die Angaben in und Tabelle sind Mittelwerte der 5 Versuchspersonen (10 Einzelbestimmungen). Weitere Einzelheiten vgl. Methodik

\begin{tabular}{|c|c|c|c|c|}
\hline \multirow{3}{*}{$\begin{array}{c}\text { Amino- } \\
\text { säuren }\end{array}$} & \multicolumn{4}{|c|}{ Konzentration der Aminosäuren nach Enteiweißung mit } \\
\hline & \multicolumn{2}{|c|}{ Sulfosalicylsäure } & \multirow{2}{*}{$\begin{array}{l}\text { Trichlor- } \\
\text { essigsäure } \\
20 \text { proz. }\end{array}$} & \multirow{2}{*}{$\begin{array}{l}\text { Ultrazentri- } \\
\text { fugation }\end{array}$} \\
\hline & 5 proz. & 10proz. & & \\
\hline Asp & $2,3 \pm 1,6$ & $1,9 \pm 3,8$ & $1,2 \pm 1,0$ & $1,7 \pm 1,0$ \\
\hline Thr & $11,8 \pm 7,4$ & $13,8 \pm 5,5$ & $14,3 \pm 8,2$ & $11,6 \pm 8,7$ \\
\hline Ser & $8,1 \pm 5,8$ & $8,9 \pm 5,1$ & $9,9 \pm 5,5$ & $9,2 \pm 4,3$ \\
\hline Glu & $18,1 \pm 3,0$ & $6,7 \pm 4,4$ & $7,3 \pm 3,3$ & $6,6 \pm 3,0$ \\
\hline Gly & $10,1 \pm 5,1$ & $10,4 \pm 5,3$ & $11,4 \pm 5,5$ & $10,3 \pm 4,4$ \\
\hline Ala & $25,4 \pm 7,1$ & $26,0 \pm 8,0$ & $27,0 \pm 8,3$ & $24,1 \pm 6,5$ \\
\hline Abu & $1,9 \pm 2,0$ & $1,7 \pm 1,5$ & $2,0 \pm 0,4$ & $1,9 \pm 0,3$ \\
\hline Val & $17,8 \pm 2,3$ & $18,2 \pm 7,1$ & $19,2 \pm 4,7$ & $19,4 \pm 4,7$ \\
\hline Cys & $5,1 \pm 3,8$ & $6,2 \pm 4,2$ & $6,0 \pm 5,0$ & $5,3 \pm 3,8$ \\
\hline Met & $3,2 \pm 1,1$ & $3.3 \pm 0,8$ & $2,8 \pm 0,8$ & $3,0 \pm 0,9$ \\
\hline Ile & $6,7 \pm 1,3$ & $6,9 \pm 1,7$ & $7,5 \pm 1,6$ & $6,5 \pm 1,2$ \\
\hline Leu & $11,7 \pm 2,6$ & $12,1 \pm 1,9$ & $12,6 \pm 2,1$ & $11,4 \pm 2,2$ \\
\hline Tyr & $7,8 \pm 2,3$ & $6,6 \pm 2,3$ & $8,6 \pm 1,7$ & $7,6 \pm 2,6$ \\
\hline Phe & $6,1 \pm 2,5$ & $5,3 \pm 2,3$ & $6,1 \pm 2,6$ & $5,6 \pm 2,0$ \\
\hline Orn & $6,2 \pm 4,6$ & $6,5 \pm 2,7$ & $7,5 \pm 5,1$ & $5,7 \pm 3,4$ \\
\hline Lys & $16,8 \pm 6,5$ & $19,2 \pm 6,0$ & $19,1 \pm 4,8$ & $14,1 \pm 4,9$ \\
\hline His & $9,7 \pm 4,5$ & $9,9 \pm 6,3$ & $10,1 \pm 4,9$ & $7,6 \pm 7,5$ \\
\hline Arg & $11,8 \pm 4,8$ & $12,6 \pm 3,9$ & $11,2 \pm 4,5$ & $10,1 \pm 3,5$ \\
\hline
\end{tabular}

zusammengestellt. Daraus geht hervor, daß trotz der verschiedenen Enteiweißungsmethoden die Konzentrationen der einzelnen Aminosäuren innerhalb der Fehlergrenzen weitgehend übereinstimmten; lediglich für die Glutaminsäure wurden nach Enteiweißung der Serumproben mit 5proz. Sulfosalicylsäure höhere Werte als bei den übrigen Verfahren beobachtet.

$\mathrm{Da}$ die mit 5proz. Sulfosalicylsäure enteiweißten Proben ohne Korrektur des $\mathrm{pH}$-Wertes direkt zur Chromatographie verwendet werden können, wurde ausschließlich diese Enteiweißungsmethode in der vorliegenden Arbeit benutzt. Sofern es nicht möglich war, die enteiweißten Proben sofort zu analysieren, wurden sie bis zur Aufarbeitung bei $-15^{\circ}$ aufbewahtt.

\section{Normalpersonen, magenresezierte und gastrektomierte Patienten}

Die Normalpersonen waren frei von erkennbaren Erkrankungen; es wurden 5 Männer (Alter 20-36 Jahre) und 2 Frauen (Alter 24 und $28 \mathrm{Jahre}$ ) untersucht. Bei den Patienten handelte es sich ausschließlich um Männer, die in folgende Gruppen eingeteilt wurden:

a) 10 Patienten mit Billroth-I-Anastomose (Alter 40-70 Jahre) b) 10 Patienten mit Billroth-II-Anastomose (Alter 50-70 Jahre), die wegen eines Ulkusleidens operiert worden waren

c) 2 gastrektomierte Patienten mit kurzer Dünndarmschlinge (Alter 57 und $67 \mathrm{Jahre}$ ) und 3 gastrektomierte Patienten mit langer Dünndarmschlinge (Alter 51, 54 und 62 Jahre) sowie jeweils 1 gastrektomierter Patient mit Roux'scher Anastomose (Alter $66 \mathrm{Jahre}$ ) und Oesophagoduodenostomie (Alter 64 Jahre), die wegen eines Magencarcinoms operiert worden waren.

Die unter a-c genannten Patienten befanden sich in einem relativ guten Allgemeinzustand; alle untersuchten Leberfunktionsproben (Bilirubin im Serum, Takata, Serumelektrophorese, SerumTransaminasen, alkalische Phosphatase, Cholinesterase und die Gerinnungsfaktoren) lagen im Normbereich. Die Entnahme der Blutproben erfolgte im nüchternen Zustand der Probanden in allen Fällen nach 12stdg. Nahrungskarenz. 


\section{Probemablzeit}

Die Probemahlzeit bestand aus $300 \mathrm{~g}$ magerem Quark, dem zur Geschmacksverbesserung der Saft einer Apfelsine sowie $120 \mathrm{mg}$ Benzoesäuresulfimid (Süßstoff, Hoechst) zugesetzt wurden.

Nach Abnahme der ersten Blutprobe der nüchternen Probanden (9 Uhr morgens) wurde die Probemahlzeit innerhalb einer $1 / 4$ Std. eingenommen. Weitere Blutentnahmen erfolgten 1/2, 1, 2 sowie 3 Stdn. nach Beendigung der Probemahlzeit.

\section{Ergebnisse}

Aminosäuren im Serum von Normalpersonen sowie von magenresezierten und gastrektomierten Patienten

Die durchschnittlichen Konzentrationen von Aminosäuren im Serum nüchterner Normalpersonen sowie magenresezierter und gastrektomierter Patienten sind in Tabelle 4 zusammengestellt. Wie aus den Mittelwerten der Tabelle hervorgeht, bestehen - mit Ausnahme der Asparagin- und Glutaminsäure - keine Unterschiede in den Aminosäuren-Konzentrationen zwischen den Normalpersonen und den Patienten mit Billroth-I-Anastomose, Billroth-II-Anastomose sowie nach Gastrektomie.

\section{Aminosäuren im Serum von Normalpersonen und gastrekto-} mierten Patienten vor und nacb einer Probemablzeit

Aus zahlreichen früheren Untersuchungen ist bekannt, daß die Konzentrationen von Aminosäuren im Serum nach einer proteinhaltigen Probemahlzeit ansteigen. Um die Kinetik dieses Anstieges besser verfolgen zu können, wurden in der vorliegenden Arbeit die Aminosäuren $1 / 2,1,2$ sowie $3 \mathrm{Stdn}$. nach Verabreichung der Probemahlzeit im Serum gemessen. Die Ergebnisse dieser Versuche sind für die Normalpersonen in $\mathrm{Ab}$ bildung 1 und für die gastrektomierten Patienten in Abbildung 2 wiedergegeben.

Bei allen Normalpersonen stiegen nach Verabreichung der Probemahlzeit die Aminosäuren-Konzentrationen mit Ausnahme derjenigen von $\alpha$-Aminobuttersäure und Cystin - im Serum an. Abgesehen von Asparaginsäure, Citrullin, Prolin und Glycin wurden die Maxima der Anstiege 1 Std. nach Beendigung der Probemahlzeit beobachtet. Die Konzentrationen der meisten Aminosäuren nahmen während der nächsten beiden Stunden (2. und 3. Std. nach Beendigung der Probemahlzeit) wieder $a b$, blieben aber über den Ausgangswerten (Nüchternwerte).

Bei den wegen eines Magencarcinoms gastrektomierten Patienten erfolgte ebenfalls nach der Probemahlzeit ein Anstieg der Aminosäure-Konzentrationen im Blut. Im Gegensatz zu den Normalpersonen waren jedoch die Resorptionsgipfel vorverlegt: Bereits $1 / 2$ Std. nach Beendigung der Probemahlzeit wurde für die Mehrzahl der Aminosäuren das Maximum erreicht. Eine nähere Betrachtung des zeitlichen Verlaufs zeigt, daß bei den Gastrektomierten im Vergleich zu den Normalpersonen die Aminosäuren im Serum zwar stärker ansteigen, andererseits aber auch wieder schneller abfallen. Daraus geht hervor, daß trotz des unterschiedlichen zeitlichen Verlaufs die Gesamtmenge der resorbierten Aminosäuren bei den Normalpersonen und den gastrektomierten Patienten etwa gleich groß war.

\section{Diskussion}

Wie in der vorliegenden Arbeit gezeigt werden konnte, sind die durchschnittlichen Konzentrationen von 21 Aminosäuren im Serum nüchterner Normalpersonen soowie magenresezierter und gastrektomierter Patienten (Billroth-I-Anastomose, Billroth-II-Anastomose und Gastrektomie) innerhalb der methodischen Fehlerbreite etwa gleich groß. Bei dieser Feststellung darf jedoch nicht übersehen werden, daß jeder Mensch ein charakteristisches Aminosäureprofil besitzt, welches - selbst innerhalb einer einheitlichen Gruppe - von Person zu Person recht verschieden sein kann; daraus ergeben sich die von uns beobachteten relativ großen Standard-Abweichungen der Mittelwerte. Es wäre durchaus denkbar, $\mathrm{da}$ sich das Aminosäurenprofil im Serum bei einem $\mathrm{Pa}$ tienten nach partieller oder totaler Magenresektion gegenüber dem präoperativen Zustand ändert; allerdings würden sich solche Änderungen - wenn überhaupt nur durch mehrfache prä- und postoperative Untersuchung!:॥ in größeren zeitlichen Abständen erkennen lassen.

Die Mittelwerte für die Konzentrationen der Asparaginsäure und der Glutaminsäure lagen bei den Normalpersonen etwas niedriger als bei den magenresezierten und gastrektomierten Patienten. Ábgesehen davon, daß sich diese Unterschiede statistisch nicht sichern ließen, sind sie auch aus methodischen Gründen ohne Bedeutung: Asparagin und Glutamin werden während der Enteiweißung des Serums und der Chromatographie in nichtreproduzierbarem Ausmaß zu den freien Aminosäuren hydrolysiert und verfälschen so die Werte für die endogenen Konzentrationen der Asparagin- und Glutaminsäure.

In einer früheren Untersuchung (7) war festgestellt worden, daß bei magenresezierten Patienten (Operation nach Billroth-I und Billroth-II) die Werte für den Gesamteiweißgehalt des Serums und für alle Fraktionen des Elektropherogramms im Normalbereich gesunder Personen liegen. Das gleiche gilt auch für die hier untersuchten 21 Aminosäuren. Diese Befunde stehen in gewissem Gegensatz zu der Beobachtung, daß sich magenresezierte Patienten häufig in einem schlechteren Allgemeinzustand befinden als Gesunde. Offenbar ist es nicht möglich, durch ein- oder mehrmalige Bestimmungen der Konzentrationen von Eiw̄iei $\beta$ und Aminosäuren im Serum einen Einblick in jene pathophysiologischen Zusammenhänge zu gewinnen, die für die Störungen der Nahrungsverwertung und die subjektiven Beschwerden bei magenresezierten und gastrektomierten Patienten verantwortlich sind.

Diese negative Feststellung veranlaßte uns, das Verhalten der Aminosäuren im Serum nach Verabreichung einer proteinhaltigen Probemahlzeit bei magenresezierten und gastrektomierten Patienten zu untersuchen und mit demjenigen bei Normalpersonen zu vergleichen. Bereits RrchmoND und GIRDwood (11) hatten nach Verabreichung von $25 \mathrm{~g}$ Casein im Serum gastrektomierter Patienten einen rascheren und höheren Anstieg von 
Tab. 4

Konzentrationen der Aminosäuren im Serum nüchterner Normalpersonen und magenresezierter Patienten Das Serum wurde mit dem gleichen Volumen 5proz. Sulfosalicylsäure enteiweiBt. Die Trennung der Aminosäuren erfolgte an Ionenaustauscher-
säulen. Normalpersonen $(n=7) ; B-I=$ Billroth-I-Anastomose $(n=10) ; B-1 I=$ Billroth-II-Anastomose (n $=10) ;$ Gastrekt. $=$ Gastrektomierte

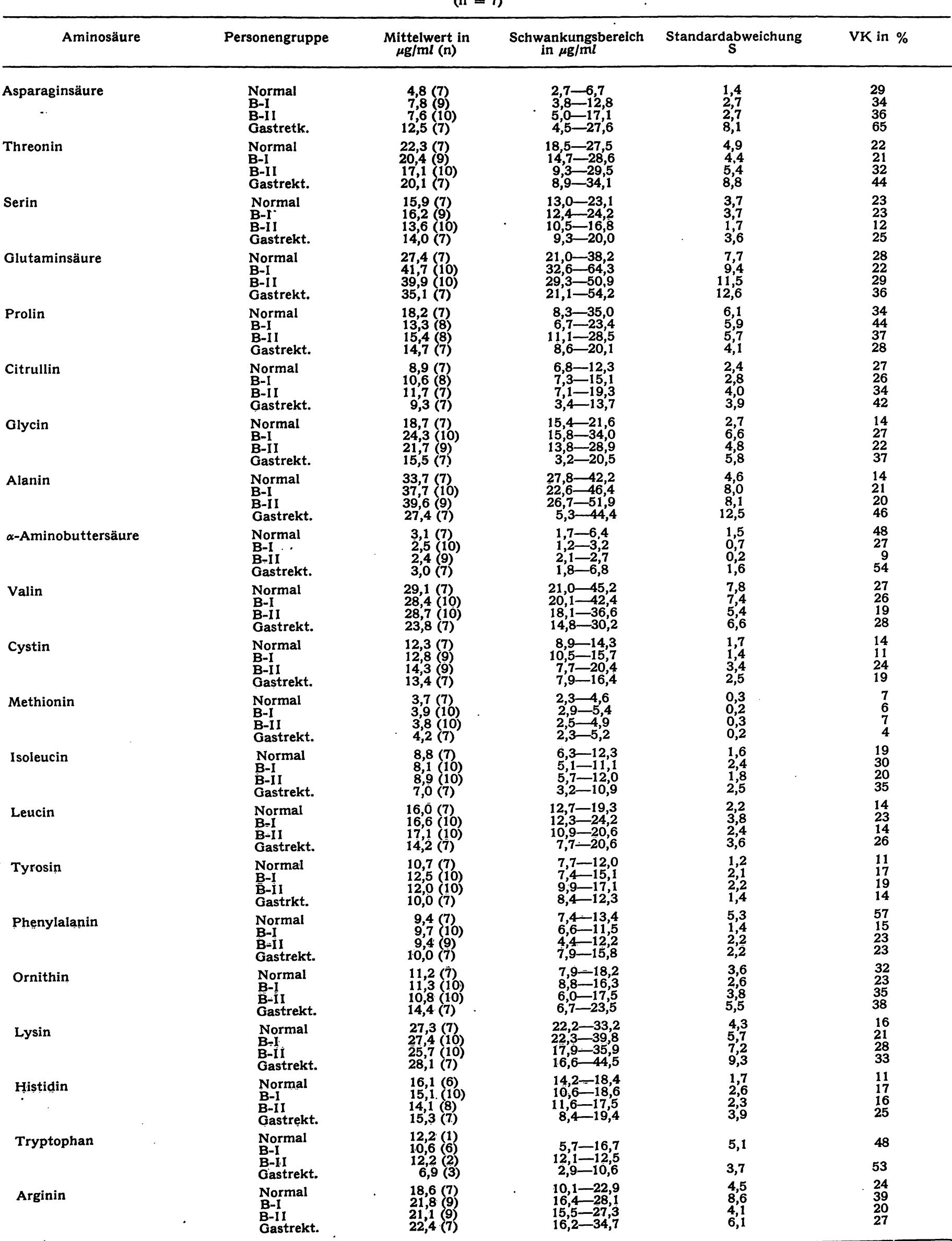



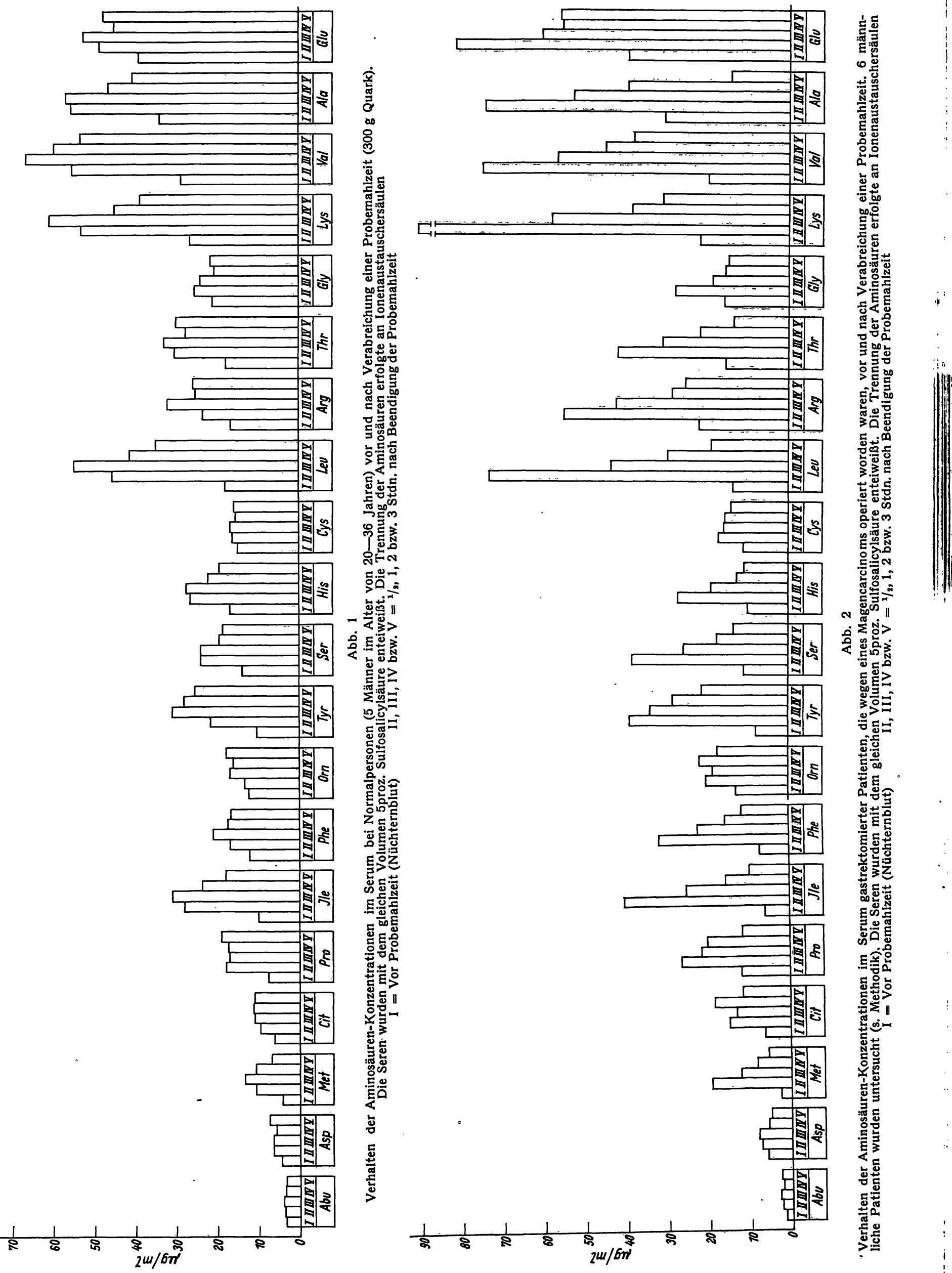

$N$ $\dot{\sum}$ Nंग 造高

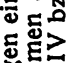
然 
Leucin, Lysin, Methionin und Phenylalanin gefunden als bei gesunden Personen. $\mathrm{Zu}$ ähnlichen Ergebnissen gelangten HART und LICK (12), die magenresezierten Patienten (Billroth-I und Billroth-II) $50 \mathrm{~g}$ Quark und $20 \mathrm{~g}$ Larosan (Calcium-Casein - Präparat der Fa. Deutsche Hoffmann-LaRoche, Grenzach/Baden) verabfolgten; $16 \%$ der untersuchten Billroth-I-Patienten und $23 \%$ der untersuchten Billroth-II-Patienten reagierten mit einem steileren Anstieg und einem schnelleren Abfall des $\alpha$-Aminostickstoffs im Serum als Normalpersonen. In eigenen Versuchen (7) mit Magenresezierten (Billroth-I und Billroth-II) wurden - im Vergleich mit Gesunden - 2 Stdn. nach einer Probemahlzeit (300 g Quark) unterschiedliche Konzentrationsänderungen der Aminosäuren im Serum beobachtet.

Um diese Untersuchungen abzurunden und gleichzeitig einen besseren Einblick in den zeitlichen Verlauf der Resorption zu gewinnen, wurden in der vorliegenden Arbeit die Konzentrationen von 21 Aminosäuren im Serum bei normalen Versuchspersonen und gastrektomierten Patienten vor sowie zu verschiedenen Zeiten nach einer Probemahlzeit bestimmt.

Dabei ergaben sich folgende wichtige Befunde:

a) Mit Ausnahme von $\alpha$-Aminobuttersäure und Cystin nabmen die Konzentrationen der Aminosäuren bei den gastrektomierten Patienten ebenso wie bei den Normalpersonen zu.

b) Das Maximum des Konzentrationsanstieges der meisten Aminosäuren wurde bei den Gastrektomierten bereits $30 \mathrm{Min}$., bei den normalen Versuchspersonen dagegen erst 60 Min. nach Beendigung der Probemahlzeit erreicht.

c) Dem rascheren Anstieg entsprach bei den gastrektomierten Patienten ein schnellerer Abfall der Aminosäuren-Konzentrationen im Serum; trotz des unterschied- lichen zeitlichen Verlaufs der Resorption war die Gesamtmenge der im Serum nachgewiesenen Aminosäuren bei beiden Gruppen etwa gleich.

Es erhebt sich die Frage, welche Bedeutung die hier gewonnenen Ergebnisse für das Verständnis der veränderten Resorptionsverhältnisse beim gastrektomierten $\mathrm{Pa}$ tienten haben. Offenbar erfolgt beim Fehlen des Magens und seinem Ersatz durch eine Dünndarmschlinge eine beschleunigte Resorption von Aminosäuren. Diese, durch quantitative Bestimmungen belegte Feststellung kann nicht über die Tatsache hinwegtäuschen, daß der Eiweiß-Stoffwechsel bei Gastrektomierten - von Ausnahmen abgesehen - im Sinne einer Katabolie gestört ist. Es erscheint deshalb gerechtfertigt anzunehmen, daß eine gesteigerte Proteolyse und Resorption für die Utilisation von Eiweiß und Aminosäuren eher ungünstig sind, eine Annahme, die auch von HART und LICK (12) geäuBert worden ist. Im übrigen sei darauf hingewiesen, daß bis heute nicht eindeutig bewiesen ist, ob zwischen der Menge und der Zusammensetzung von oral zugeführten Eiweiß- oder Aminosäurengemischen einerseits und dem Konzentrationsanstieg von Aminosäuren im Serum andererseits ein Zusammenhang besteht. Für einen solchen $\mathrm{Zu}$ sammenhang sprechen die Arbeiten von Denton und Elvehjem (13) sowie von Richmond und Girdwood (11), während BoRGSTRÖM und Mitarbeiter (14) sowie JERvis und SMYTH (15) zu entgegengesetzten Feststellungen gelangten; KNAUFF und Mitarbeiter (4) kommen zu dem Schluß, daß der mehr oder weniger starke Anstieg von Aminosäuren im Serum nach Zufuhr eines proteinhaltigen Präparates in erster Linie von seiner Umsetzbarkeit im intermediären Stoffwechsel und erst in zweiter Linie von der zugeführten Menge abhängt.

Wir danken Herrn Dr. W. M. Bartsch für die Mithilfe bei der Untersuchung der Patienten. Fräulein Maria NatschKe sind wir für ihre Mitarbeit zu Dank verpflichtet.

\section{Literatur}

1. Iber, F. L., H. Rosen, S. M. Levenson und T. C. Chalmers, J. Laborat. Clin. Med. S. Louis 50, 417 (1957). - 2. Gerok, W., Dtsch. med. Wschr. 88, 1188 (1963). - 3. KnaufF, H. G., D. SEYBold und B. Miller, Klin. Wschr. 42, 326 (1964). - 4. Knauff, H. G., D. Seybold und A. Kanters, Klin. Wschr. 43. 382 (1965). - 5. Knauff, H. G., H. HametmanN, D. Seybold und A. Kanters, Klin. Wschr. 44, 147 (1966). - 6. Pristrerer, H. G., Langenbecks Arch. klin. Chir. 301, 189 (1962). - 7. Bartsch, W. M., A. GütgemanN, H. W. Schreiber und J. Breuer, Langenbecks Arch. klin. Chir. 317, 140 (1967). - 8. Hamilton, P. B., Analytic. Chem. 30, 914 (1958). - 9. Breuer, J., H. IsE, E. Döllefeld und H. Breuer, diese Z. 4, 267 (1966), -
10. Stekelenburg, van G. J. und J. Desplanque, Technicon Instruments Company Ltd., 4th Amino Acid Colloquium, London, p. 83 (1966). - 11. Richmond, J. und R. H. Girdwood, Clin. Sc. London 22, 301 (1962). - 12. HAR.T, W. und R. F. LICK, Med. Klin. 60, 1349 (1965). - 13. Denton, A. E. und C. A. ElvehJem, J. biol. Chemistry 206, 449 (1954). - 14. Borgström, B., A. DahtQuist, G. LundH und J. SJövalL, J. Clin. Invest. 36, 1521 (1957). -15. Jervis, E. L. und D. H. Smyth, J. Physiol. 149, 433 (1959). - 16. Peterson, E. A. und H. A. Sober, Analytic. Chem. 31, 857 (1959). - 17. PIEZ, K. A. und L. Morris, Analytic. Biochem. 1, 187 (1960).

Prof. Dr. H. Breuer Institut für Klinische Biochemie der Universität Bonn Bonn-Venusberg 